TROPICAL MEDICINE SERIES

\title{
Chancroid: clinical manifestations, diagnosis, and management
}

\section{A Lewis}

Sex Transm Infect 2003;79:68-71

Chancroid is a sexually transmitted disease (STD) caused by the Gram negative bacterium Haemophilus ducreyi and is characterised by necrotising genital ulceration which may be accompanied by inguinal lymphadenitis or bubo formation. $H$ ducreyi is a fastidious organism which is difficult to culture from genital ulcer material. DNA amplification techniques have shown improved diagnostic sensitivity but are only performed in a few laboratories. The management of chancroid in the tropics tends to be undertaken in the context of syndromic management of genital ulcer disease and treatment is usually with erythromycin. A number of single dose regimens are also available to treat $H$ ducreyi infection. Genital ulceration as a syndrome has been associated with increased transmission of human immunodeficiency virus (HIV) infection in several cross sectional and longitudinal studies. Effective and early treatment of genital ulceration is therefore an important part of any strategy to control the spread of HIV infection in tropical countries.

Patrick Clements Clinic, Central Middlesex Hospital, Northwest London Hospitals NHS Trust, London NW10 7NS, UK

Correspondence to: Lydia Clinic, 1st Floor Lambeth Wing, St Thomas's Hospital, Lambeth Palace Road London SE 1 7EH, UK david.lewis@ gstt.sthames.nhs.uk

Accepted for publication 2 September 2002

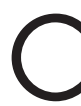
hancroid is a sexually transmitted infection caused by the Gram negative bacterium Haemophilus ducreyi. The disease manifests as genital ulceration which may be accompanied by regional lymphadenitis and bubo formation. Chancroid may also be spread to other anatomical sites by auto-inoculation, a clinical feature first demonstrated experimentally by Ducrey in $1889 .{ }^{1}$ It occurs sporadically in the developed world, usually in individuals who have recently returned from chancroid endemic areas or occasionally within the context of localised urban outbreaks which may be associated with commercial sex work..$^{2-4}$ Within the resource poor areas of the world, however, chancroid remains a major cause of the genital ulceration syndrome. Recent reports from South East Asia and Africa suggest that the incidence of chancroid may be declining in the face of a rapidly rising incidence of genital herpes. ${ }^{5-7}$ This observation has fuelled recent debate as to the feasibility of chancroid eradication. ${ }^{5}$ Genital ulceration has been shown to be a major co-factor in the transmission of human immunodeficiency virus type 1 (HIV-1) infection both through cross sectional cohort studies and prospective longitudinal studies. ${ }^{8-10}$ Therefore, effective diagnosis and treatment of chancroid may play an important part in slowing down the
HIV-1 epidemic in those parts of the world where both diseases are prevalent.

\section{CLINICAL PRESENTATION}

It is believed, though unproved, that $H$ ducreyi initiates an infective process within the genital skin after the formation of epidermal microabrasions during sexual intercourse. A tender erythematous papule may develop 4-7 days later before progressing to the pustular stage. An estimated delivery dose of approximately 30 colony forming units of $H$ ducreyi organisms has been reported to cause a papule formation rate of $95 \%$ and a pustule formation rate of $69 \%$ in the experimental human challenge model. ${ }^{11}$ Pustules often rupture after a further 2-3 days to form painful shallow ulcers with granulomatous bases and purulent exudates (fig 1). The ulcer edge is typically ragged and undermined. Clinical observations from the preantibiotic era demonstrate the chronicity of chancroid ulceration which can take several weeks or months to resolve in the absence of effective antimicrobial therapy. ${ }^{12}{ }^{13}$ Naturally occurring chancroid is usually more prevalent in men than women. This sex difference has also been observed experimentally in both humans and macaques. ${ }^{14}{ }^{15}$ Lesions typically occur on the prepuce and frenulum in men and on the vulva, cervix, and perianal area in women. Complications include phimosis in men and further phagedenic ulceration due to secondary bacterial infection. Extragenital cases of chancroid with lesions on inner thighs, breasts, and fingers have been reported but are rarely seen in clinical practice. Painful, tender inguinal lymphadenitis typically occurs in up to $50 \%$ of cases and the lymph nodes may develop into buboes. The lymphadenopathy is usually unilateral and tends to be more prevalent in men (fig 2). If not aspirated or drained through incision, fluctuant buboes can rupture spontaneously.

It has been reported that the proportion of genital ulcers attributable to herpes simplex virus (HSV) in sub-Saharan Africa is increasing and

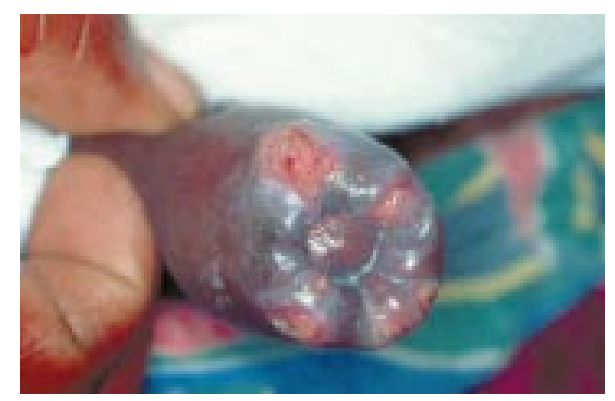

Figure 1 Penile ulceration due to chancroid. 


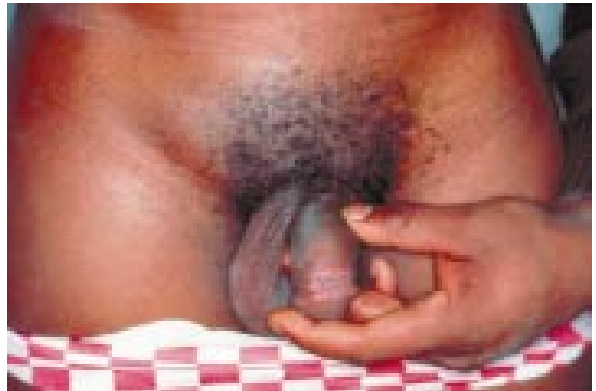

Figure 2 Right sided inguinal bubo and penile ulcer in a man with chancroid.

mixed infections with two or more of $H$ ducreyi, Treponema pallidum, and HSV are well described.$^{16-18}$ The effect of concurrent HIV infection on the clinical progression of chancroid is unclear at this time. Published data suggest that HIV seropositive men have increased numbers of genital ulcers which may heal at slower rates. ${ }^{19} 20$ This is of importance in view of the epidemiological synergy that co-exists between HIV infection and genital ulceration in areas of the world where both are common. ${ }^{8}$ HIV-1 has been detected in chancroid ulcer material obtained from both men and women. ${ }^{21}{ }^{22}$ In addition, chancroid ulcers contain numerous CD4 positive T lymphocytes which could increase the susceptibility of an individual infected with $H$ ducreyi to subsequent infection by HIV. ${ }^{23}$

\section{DIAGNOSIS}

Clinical diagnosis and laboratory culture of $H$ ducreyi were used as "gold standards" for the diagnosis of chancroid in the past. The advent of DNA amplification tests has recently demonstrated both to be inaccurate measures of the true prevalence of $H$ ducreyi infection among patients with genital ulcer disease. Physical examination findings have a low sensitivity and specificity for diagnosing primary syphilis, chancroid, and genital herpes, even in areas where these diseases are common and where attending physicians are experienced in the management of genital ulcer disease. ${ }^{24-26}$ The sensitivity of $H$ ducreyi culture relative to the multiplex polymerase chain reaction (M-PCR) has been shown to be approximately $75 \%$ in studies which have used genital ulcer derived swabs. ${ }^{27}{ }^{28}$ Currently available clinically based and research based methodologies for the diagnosis of chancroid have previously been reviewed by the author. ${ }^{29}$ It should be pointed out that Gram stained ulcer material should not be examined as a means to diagnose chancroid owing to poor sensitivity and specificity of this test. ${ }^{30}$

$H$ ducreyi is a fastidious bacterium requiring a relatively expensive nutritive base to grow on and is an extremely difficult organism to culture from clinical specimens in the hands of inexperienced laboratory staff. As a result, conventional laboratory culture facilities are often not available in STD clinics or simply not affordable in resource poor countries. In those clinical settings with laboratory support, clinicians are often faced with the dilemma of whether to treat a patient empirically for chancroid at the first visit or whether to request staff in their microbiology laboratory to provide a suitable medium with which to culture $H$ ducreyi on a subsequent day in the hope that the patient is not lost to follow up. Even if culture facilities are available, it often takes several days for results to become available.

The role of Stuart's, Amies', and thioglycolate hemin based transport media has been evaluated as transport media for $H$ ducreyi. ${ }^{31}$ Increased survival of $H$ ducreyi from less than 24 hours to up to 4 days was seen when specimens were held at $4^{\circ} \mathrm{C}$. The use of transport media in locations with a refrigeration facility may overcome the significant cost of distribution of culture media with short shelf lives to clinics where the disease is only seen sporadically. There did not appear to be any major advantage in the overall rate of recovery of $H$ ducreyi using transport media compared to direct plating.

Most $H$ ducreyi strains grow best at $33^{\circ} \mathrm{C}$ in a humid atmosphere containing 5\% carbon dioxide. ${ }^{32}$ Improved $H$ ducreyi isolation rates are seen using microaerophilic conditions in which culture plates inoculated with $H$ ducreyi are incubated in a closed anaerobic jar without a catalyst but with two $\mathrm{CO}_{2}$ and $\mathrm{H}_{2}$ generating sachets. ${ }^{33}$ Numerous artificial media have been developed and have been reviewed elsewhere. ${ }^{29}{ }^{34}$

Several DNA amplification based techniques have been developed in an attempt to improve the sensitivity of the laboratory diagnosis of chancroid. ${ }^{28}{ }^{35-38}$ The technique of M-PCR involves the addition of multiple primer pairs to the reaction mixture in order to simultaneously amplify distinct DNA sequences from different targets in the processed lesion material. The research based M-PCR described by Orle et al offers a highly sensitive and specific way to detect the three most common aetiological agents of genital ulcer disease-namely, HSV, Treponema pallidum, and $H$ ducreyi. ${ }^{28}$ Specimens for M-PCR may easily be transported from the STD clinic to a remote laboratory and can be stored at $-70^{\circ} \mathrm{C}$ if required for batch testing. The ability to perform DNA amplification based techniques requires access to laboratories with specialised molecular biological expertise. As such, this expensive technology will continue to have a role in research and outbreak investigation but is not likely to be made available to clinicians in most worldwide settings where patients with chancroid seek STD care.

\section{SYNDROMIC MANAGEMENT}

The World Health Organization (WHO) developed and advocates the use of syndromic management to address the limitations of both aetiological and presumptive aetiological diagnosis and management of symptomatic STDs. ${ }^{39}$ The principle behind this approach is that patients are treated at the first visit with a combination of antimicrobials that will treat the local probable aetiological agents. Syndromic management flow charts for the management of genital ulcers have been prepared which provide simple instructions to health providers on how to manage the patient and his/her sexual contact(s) (fig 3). ${ }^{40}$ The process requires little or no clinical description of the ulcer itself and does not require laboratory identification of the causative pathogen(s). Syndromic management has been proved to be more successful than a hierarchical algorithm or clinical diagnosis in the management of genital ulcer disease in Rwanda. ${ }^{41}$ It is envisaged that M-PCR will have an important role in validating syndromic algorithms for the management of genital ulcer disease as the aetiology of this syndrome varies geographically and over time. It may be appropriate to perform laboratory diagnostic and antimicrobial susceptibility testing on specimens from ulcers of patients failing to respond to antimicrobial therapy in situations where reinfection from an untreated partner has been excluded.

\section{TREATMENT}

Recommended and alternative treatment regimens from the WHO, the Centers for Disease Control and Prevention (CDC), and the United Kingdom's Clinical Effectiveness Group are presented in table $1 .^{42-44}$ There is some debate concerning the duration of ciprofloxacin therapy for chancroid; the WHO recommends a single $500 \mathrm{mg}$ oral dose whereas the CDC recommends $500 \mathrm{mg}$ twice daily for 3 days. A recent double blind randomised controlled trial in Kenya demonstrated comparable cure rates for both single dose ciprofloxacin (92\%) and a l week course of erythromycin $(91 \%) .{ }^{45}$ Pregnant women should be treated with either erythromycin or ceftriaxone regimens. Patients with underlying immunosuppression due to HIV infection should be carefully followed up as reduced healing of genital ulcers and persistence of $H$ ducreyi in the lesions has been reported in this group. ${ }^{196-48}$ There also appears to be an increased likelihood of treatment failure in uncircumcised individuals with 


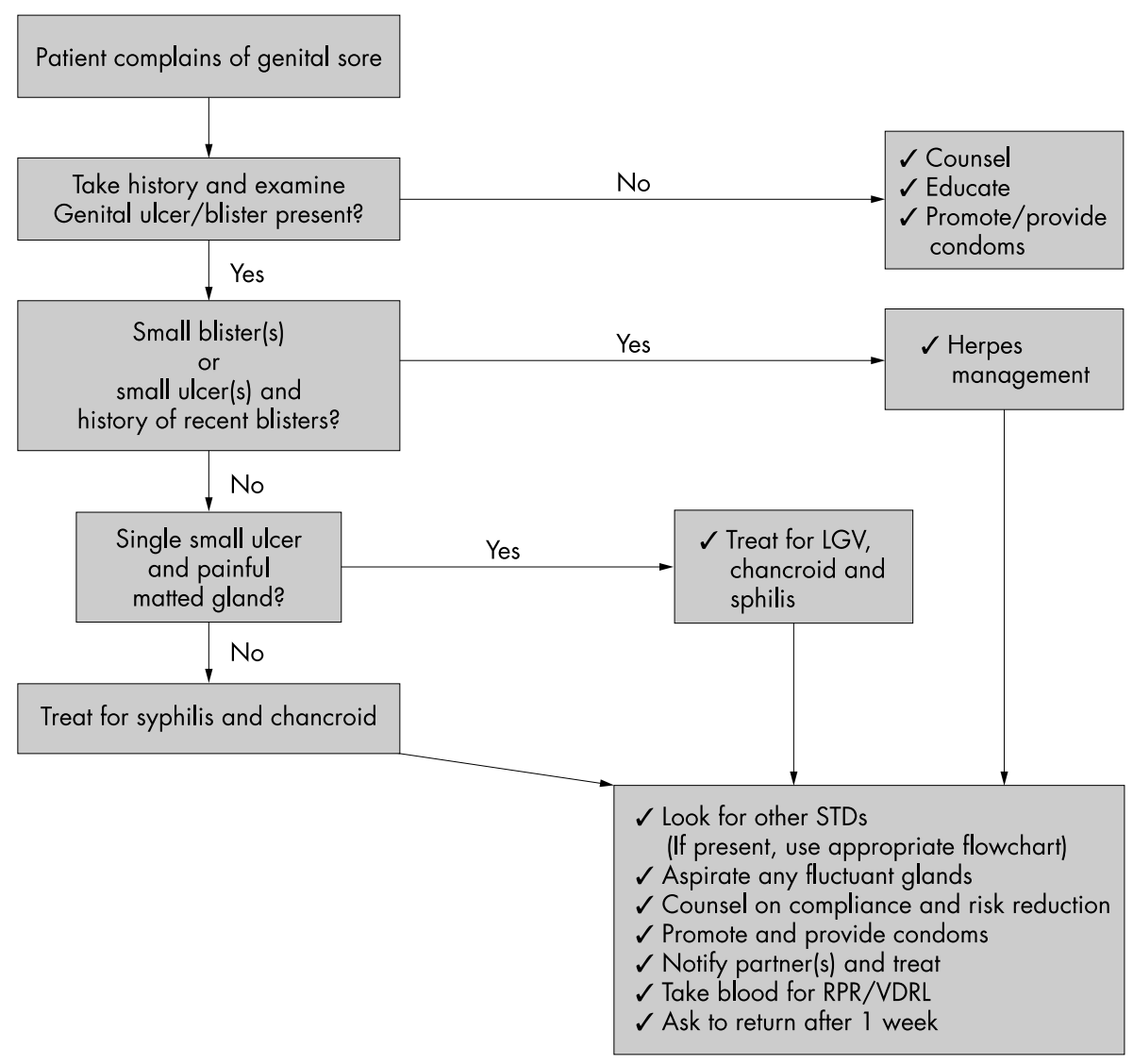

Figure 3 Syndromic protocol C for genital ulcer disease evaluated in Lesotho by Htun et $a^{40}$ (reproduced from Sex Transm Infect

1998;74(Suppl 1):S23-8 with the permission of Ye Htun and the BM Publishing Group).

chancroid. ${ }^{1948} 49$ Treatment failures have been reported in African patients treated with single doses of either intramuscular ceftriaxone or oral fleroxacin. ${ }^{19}{ }^{48}$ Undiagnosed co-existing HSV infection, particularly in immunosuppressed HIV seropositive patients, may also account for some of the observed cases where treatment has failed to cure chancroid.

Plasmid mediated antimicrobial resistance has been documented for a number of agents, including penicillins, tetracyclines, chloramphenicol, sulfonamides, and aminoglycosides. ${ }^{50}$ Much less is known about chromosomally mediated resistance to antimicrobials in $H$ ducreyi but decreased susceptibility has been described for penicillin, ciprofloxacin, ofloxacin, and trimethoprim. ${ }^{50}$ There is little, if any, antimicrobial surveillance occurring in countries where chancroid is common. Based on the emergence of resistant strains in Rwanda, ${ }^{51}$ the WHO has recommended that chancroid is not treated with trimethoprim/sulfamethoxazole based regimens unless the antimicrobial susceptibility profiles of local $H$ ducreyi isolates are known. ${ }^{42}$

Fluctuant buboes should be aspirated in order to provide symptomatic relief for the patient and to avoid the further complication of spontaneous rupture. ${ }^{42} 52$ Incision and drainage of fluctuant buboes, with subsequent packing of the wound, has also been recommended as an effective management strategy for chancroid and avoids the need for frequent bubo re-aspirations..$^{53}$ This latter study was performed in New Orleans and not in the tropics; it is as yet unclear as to whether a similar approach in the tropics would be associated with an increased postoperative morbidity.

\section{OTHER MANAGEMENT ISSUES}

In countries where the practice of syndromic management is adopted, patients with genital ulcers should receive treatment for both chancroid and syphilis. Therapy for granuloma inguinale should be added to the regimen in endemic areas and treatment for lymphogranuloma venereum should be given if inguinal buboes are present. Patients with genital ulcers should be seen after treatment to ensure that healing has occurred, to exclude the possibility of reinfection, and to ensure that partner notification has taken place. All patients with genital ulcers should receive appropriate health education and safer sex practices should be discussed. Serological

Table 1 Recommended treatment regimens for chancroid from the World Health Organization (WHO), the Centers for Disease Control and Prevention (CDC), and the United Kingdom Clinical Effectiveness Group (CEG)

\begin{tabular}{llllll}
\hline Antimicrobial & Dose & Frequency & Duration & Route & Recommending body \\
\hline Erythromycin & $500 \mathrm{mg}$ & $\mathrm{tds}$ & 7 days & oral & WHO \\
Erythromycin & $500 \mathrm{mg}$ & qds & 7 days & oral & CDC, CEG \\
Azithromycin & $1 \mathrm{~g}$ & single dose & - & oral & CDC, CEG \\
Ceftriaxone & $250 \mathrm{mg}$ & single dose & - & im & WHO, CDC, CEG \\
Ciprofloxacin & $500 \mathrm{mg}$ & single dose & - & oral & WHO, CEG \\
Ciprofloxacin & $500 \mathrm{mg}$ & bd & 3 days & oral & CDC, CEG \\
Spectinomycin & $2 \mathrm{~g}$ & single dose & - & im & WHO \\
\hline \multirow{2}{*}{ bd = twice daily, tds = three times daily, qds = four times daily, im = intramuscular. }
\end{tabular}


screening for both syphilis and HIV infection should be offered at the time of genital ulcer presentation and again after 3 months at the end of the window period for both diseases. In clinics where diagnostic facilities are available, patients should be appropriately screened for all pathogens causing genital ulceration as well as for other STDs.

\section{CONCLUSIONS}

Chancroid remains an important cause of the genital ulceration syndrome in the tropics where erythromycin has been the mainstay of therapy. Single dose oral azithromycin or ciprofloxacin and intramuscular ceftriaxone regimens offer advantages in terms of improved patient compliance. There are some data to suggest that HIV seropositive and uncircumcised patients are more likely to fail single dose therapeutic regimens and so these groups of patients need more intensive follow up. WHO recommended syndromic management for genital ulceration includes therapy for both chancroid and syphilis. In those parts of the world where diagnostic facilities exist, the diagnosis of chancroid is normally made by laboratory culture of $H$ ducreyi. The more sensitive DNA amplification techniques remain research tools at the present time.

\section{REFERENCES}

1 Ducrey A. Experimentelle Untersuchungen uber den Ansteckungsstof des weichen Schankers und uber die Bubonen. Monats Prakt Dermatol 1889;9:387-405.

2 Hammond GW, Slutchuk M, Scatliff J, et al. Epidemiologic, clinical,

laboratory, and therapeutic features of an urban outbreak of chancroid in North America. Rev Infect Dis 1980;2:867-79.

3 Schmid GP, Sanders LL Jr, Blount JH, et al. Chancroid in the United States. Reestablishment of an old disease. JAMA 1987;258:3265-8.

4 DiCarlo RP, Armentor BS, Martin DH. Chancroid epidemiology in New Orleans men. J Infect Dis 1995;172:446-52.

5 Steen R. Sex, soap and antibiotics: the case for chancroid eradication. Int J STD AIDS 2001;12(Suppl 2): 147.

6 Kharsany ABM, Mahabeer Y, Connolly C, et al. Changing aetiology of genital ulcer disease (GUD) in STD clinic attenders with a rising HIV prevalence. 13th International AIDS Conference. Durban, 2000.

7 Dangor Y, Htun Y, Radebe F, et al. Epidemiological, clinical and microbiological features of genital ulcer disease in southern Africa-influence of HIV infection. Lesedi Afrika'99. Sun City, 1999.

8 Fleming DT, Wasserheit JN. From epidemiological synergy to public health policy and practice: the contribution of other sexually transmitted diseases to sexual transmission of HIV infection. Sex Transm Infect 1999;75:3-17.

9 Cameron DW, Simonsen JN, D'Costa $L$, et al. Female to male transmission of human immunodeficiency virus type 1: risk factors for seroconversion in men. Lancet 1989;ii:403-407.

10 Plummer FA, Simonsen JN, Cameron DW, et al. Cofactors in male-female sexual transmission of human immunodeficiency virus type 1 . $J$ Infect Dis 1991;163:233-9.

11 Al-Tawfiq JA, Thornton AC, Katz BP, et al. Standardization of the experimental model of Haemophilus ducreyi infection in human subjects. $J$ Infect Dis 1998;178:1684-7.

12 Rauschkolb JE. Circumcision in treatment of chancroidal lesions of male genitalia. Arch Dermatol Syphilol 1939;39:319-28.

13 Trees DL, Morse SA. Chancroid and Haemophilus ducreyi: an update. Clin Microbiol Rev 1995:8:357-75.

14 Bong CTH, Harezlak J, Katz BP, et al. Men are more susceptible than women to pustule formation in the experimental model of Haemophilus ducreyi infection. Sex Transm Dis 2002;29:114-18.

15 Totten PA, Morton WR, Knitter GH, et al. A primate model for chancroid. J Infect Dis 1994;169:1284-90.

16 Chen CY, Ballard RC, Beck-Sague CM, et al. Human immunodeficiency virus infection and genital ulcer disease in South Africa: the herpetic infection. Sex Transm Dis 2000;27:21-9.

17 O'Farrell N. Increasing prevalence of genital herpes in developing countries: implications for heterosexual HIV transmission and STI contro programmes. Sex Transm Infect 1999;75:377-84

18 Morse SA. Etiology of genital ulcer disease and its relationship to HIV infection [editorial]. Sex Transm Dis 1999;26:63-5.

19 Tyndall M, Malisa M, Plummer FA, et al. Ceftriaxone no longer predictably cures chancroid in Kenya. J Infect Dis 1993;167:469-71.

20 King R, Choudhri SH, Nasio J, et al. Clinical and in situ cellular responses to Haemophilus ducreyi in the presence or absence of HIV infection. Int J STD AIDS 1998;9:531-6.

21 Plummer FA, Wainberg MA, Plourde $P$, et al. Detection of human immunodeficiency virus type 1 (HIV-1) in genital ulcer exudate of HIV-1-infected men by culture and gene amplification. J Infect Dis $1990 ; 161: 810-11$
22 Kreiss JK, Coombs R, Plummer F, et al. Isolation of human immunodeficiency virus from genital ulcers in Nairobi prostitutes. J Infect Dis 1989;160:380-4

23 King R, Gough J, Ronald A, et al. An immunohistochemical analysis of naturally occurring chancroid. J Infect Dis 1996;174:427-430.

24 Dangor Y, Ballard RC, Exposto FL, et al. Accuracy of a clinical diagnosis of genital ulcer disease. Sex Transm Dis 1990;17:184-9.

25 DiCarlo RP, Martin DH. The clinical diagnosis of genital ulcer disease in men. Clin Infect Dis 1997;25:292-8.

26 Chapel TA, Brown WJ, Jeffres $C$, et al. How reliable is the morphological diagnosis of penile ulcerations? Sex Transm Dis 1997;4:150-2.

27 Morse SA, Trees DL, Htun Y, et al. Comparison of clinical diagnosis and standard laboratory and molecular methods for the diagnosis of genital ulcer disease in Lesotho: association with human immunodeficiency virus infection. J Infect Dis 1997; 175:583-9.

28 Orle KA, Gates CA, Martin DH, et al. Simultaneous PCR detection of Haemophilus ducreyi, Treponema pallidum, and herpes simplex virus types 1 and 2 from genital ulcers. J Clin Microbiol 1996;34:49-54.

29 Lewis DA. Diagnostic tests for chancroid. Sex Transm Infect 2000;76: 137-41

30 Albritton WL. Biology of Haemophilus ducreyi. Microbiol Rev 1989;53:377-89.

31 Dangor Y, Radebe F, Ballard RC. Transport media for Haemophilus ducreyi. Sex Transm Dis 1993;20:5-9.

32 Schmid GP, Faur YC, Valu JA, et al. Enhanced recovery of Haemophilus ducreyi from clinical specimens by incubation at 33 versus $35 \circ \mathrm{C}$. J Clin Microbiol 1995;33:3257-9.

33 Sturm AW, Zanen HC. Characteristics of Haemophilus ducreyi in culture. J Clin Microbiol 1984;19:672-4

34 Morse SA. Chancroid and Haemophilus ducreyi. Clin Microbiol Rev 1989:2:137-57.

35 Chui L, Maclean I, Marusyk R. Development of the polymerase chain reaction for diagnosis of chancroid. J Clin Microbiol 1993;31:659-64.

36 Johnson SR, Martin DH, Cammarata C, et al. Development of a polymerase chain reaction assay for the detection of Haemophilus ducreyi. Sex Transm Dis 1994;21:13-23

37 Parsons LM, Waring AL, Otido J, et al. Laboratory diagnosis of chancroid using species-specific primers from Haemophilus ducreyi groEL and the polymerase chain reaction. 1995:23:89-98.

38 West B, Wilson SM, Changalucha J, et al. Simplified PCR for detection of Haemophilus ducreyi and diagnosis of chancroid. J Clin Microbiol 1995;33:787-90.

39 Dallabetta GA, Gerbase AC, Holmes KK. Problems, solutions, and challenges in syndromic management of sexually transmitted diseases. Sex Transm Infect 1998;74(Suppl 1):S1-11.

40 Htun Y, Morse SA, Dangor Y, et al. Comparison of clinically-directed, disease specific, and syndromic protocols for the management of genital ulcer disease in Lesotho. Sex Transm Infect 1998:74(Suppl 1):S23-8.

41 Bogaerts J, Vuylsteke B, Martinez-Tello WM, et al. Simple algorithms for the management of genital ulcers: evaluation in a primary health care centre in Kigali, Rwanda. Bull World Health Organ 1995;73:761-7.

42 World Health Organization. Management of sexually transmitted diseases. (WHO/GPA/TEM/94.1 Rev 1 ed). Geneva: WHO, 1997.

43 Schmid GP. Treatment of chancroid, 1997. Clin Infect Dis 1999;28(Suppl 1):S14-20.

44 National guideline for the management of chancroid. Clinical Effectiveness Group (Association of Genitourinary Medicine and the Medical Society for the Study of Venereal Diseases). Sex Transm Infect 1999;75(Suppl):S43-5

45 Malonza IM, Tyndall MW, Ndinya-Achola JO, et al. A randomized, double-blind, placebo-controlled trial of single-dose ciprofloxacin versus erythromycin for the treatment of chancroid in Nairobi, Kenya. J Infect Dis 1999;180:1886-93

46 Kimani J, Bwayo JJ, Anzala AO, et al. Low dose erythromycin regimen for the treatment of chancroid. East Afr Med J 1995;72:645-8.

47 Behets FM, Liomba G, Lule G, et al. Sexually transmitted diseases and human immunodeficiency virus control in Malawi: a field study of genita ulcer disease. J Infect Dis 1995;171:451-5.

48 MacDonald KS, Cameron DW, D'Costa LJ, et al. Evaluation of fleroxacin (RO 23-6240) as single-oral-dose therapy of culture-proven chancroid in Nairobi, Kenya. Antimicrob Agents Chemother 1989;33:612-14

49 Tyndall MW, Agoki E, Plummer F, et al. Single dose azithromycin for treatment of chancroid: a randomized comparison with erythromycin. Sex Transm Dis 1994:21:231-4.

50 Lewis DA. Chancroid: from clinical practice to basic science. AIDS Patient Care STDs 2000;14:19-36.

51 Van Dyck E, Bogaerts J, Smet H, et al. Emergence of Haemophilus ducreyi resistance to trimethoprim-sulfamethoxazole in Rwanda. Antimicrob Agents Chemother 1994;38:1647-8

52 Viravan C, Dance DAB, Ariyarit C, et al. A prospective clinical and bacteriologic study of inguinal buboes in Thai men. Clin Infect Dis 1996;22:233-9.

53 Ernst AA, Marvez-Valls E, Martin DH. Incision and drainage versus aspiration of fluctuant buboes in the emergency department during an epidemic of chancroid. Sex Transm Dis 1995;22:217-20. 